\title{
Research on the Innovative Practice of Intangible Cultural Heritage Chaozhou Embroidery in Cultural and Creative Products
}

\author{
Zhexin $\mathrm{Liu}^{1, *}$ \\ ${ }^{1}$ Zhuhai College of Jilin University, Zhuhai, Guangdong, China \\ *Corresponding author. Email: 38383822@qq.com
}

\begin{abstract}
Starting from the historical background of Chaozhou embroidery, this article introduces the characteristics and categories, crafts and patterns, application and development of embroidery culture. It can be concluded that the cultural inheritors of the tide embroidery are old, the embroidery workers are aging, and there is a lack of successors; the innovation ability is insufficient and it failed to keep pace with the times; the general public lacks effective ways to understand the Chaozhou embroidery in daily life; the current situation of the current market of Chaozhou embroidery is narrow and so on. Combined with the booming social dynamics of cultural and creative products, this paper explores the design of Chaozhou embroidery cultural and creative products. Through research and practice, the innovative path of how to protect and inherit the Chaozhou Embroidery skills in the development of the modern market is given. It can be concluded that the protection of Chaozhou embroidery must be carried out at the same time from the two aspects of preservation protection and productive protection, in order to make the traditional handicraft of Chaozhou embroidery shine and better promote the development of Chaozhou embroidery culture. It is hoped to make a little contribution to the development, inheritance and protection of Chaozhou embroidery skills.
\end{abstract}

Keywords: Chaozhou embroidery, Cultural and creative products, Innovation.

\section{INTRODUCTION}

On October 2, 2020, General Secretary Xi Jinping went to Chaozhou to inspect the intangible cultural heritage, watched live production demonstrations by representatives of the inheritors of the intangible cultural heritage project, and had a cordial exchange with them to learn about the inheritance of Chaozhou traditional skills. Xi Jinping pointed out that Chaozhou culture has distinct regional characteristics and is an important part of Lingnan culture and an important branch of

*Project: This article is the 2019 Innovation and Cultivation Project of Zhuhai College of Jilin University "Innovative Research on Lingnan Chaozhou Embroidery in Cultural and Creative Products Against the Background of the GuangdongHong Kong-Macao Greater Bay Area" (Project No.: 2018XJCQ023), and one of the phased research results supported by the 2020 Guangdong university scientific research platform and project "Innovative Research on Lingnan Tide Embroidery in Cultural and Creative Products in the Context of Guangdong-Hong Kong-Macao Greater Bay Area" (Project No.: 2020WTSCX128).
Chinese culture. Chaozhou intangible cultural heritage represented by Chaozhou embroidery, Chaozhou porcelain, Chaozhou sculpture, Chaozhou opera, Gongfu tea, Chaozhou cuisine, etc., are treasures of Chinese culture. It is necessary to strengthen the protection and inheritance of intangible cultural heritage, and actively cultivate inheritors to make the intangible cultural heritage bloom more fascinating.

Chaozhou embroidery began in the Tang and Song dynasties and flourished in the Ming and Qing dynasties. It is a major branch of Guangdong embroidery, one of the four famous embroideries in China. It has a long history and inheritance, and a strong folk decoration style. It is an embroidery art of the Chinese nation with local characteristics. It is unique among the four famous embroideries. Chaozhou embroidery was listed in the first batch of national intangible cultural heritage list in 2006, and was listed in the first batch of national traditional craft revitalization list in May 2018. In 
recent years, Chaozhou embroidery craftsmen have been determined to innovate on the basis of inheritance, and the needle technique of Chaozhou embroidery has been greatly improved. It enjoys a high reputation in China and foreign countries and is a treasure in the treasure house of embroidery art in China. Since the reform and opening up, highquality Chaozhou embroidery has been selected by the Ministry of Foreign Affairs as a national gift, and the leaders of the country will present gifts to foreign heads of state and other distinguished guests.

\section{THE ARTISTIC CHARACTERISTICS AND FORMS OF CHAOZHOU EMBROIDERY}

The theme content and patterns of Chaozhou embroidery are unique. Chaozhou embroidery is both folk art and practical appreciation. The main products are hanging screens, banners, screens, bed curtains, colored eyebrows, costumes, banners, treasure covers, etc. On the basis of Chaozhou folk culture, Chaozhou wood carving, Chaocai and other traditional crafts are integrated, forming a plump, undulating and varied, orderly and disorderly, colorful, fine organization, and colorful overall The style gives people a noble, elegant, lively and joyful artistic effect, with strong local characteristics. Chaozhou embroidery has a wide range of subjects and is rich in regional characteristics, including characters, animals, flowers, utensils, marine fish and shrimps, and southern fruits. The characters emphasize the situation, while the flowers and birds emphasize the dynamics. Embroidery workers used the empty composition with blank space to arrange the dragon body and phoenix tail in the auspicious form of the dragon and the phoenix in a reasonable manner to avoid the scattered pattern layout and the stiff picture. It is emphasized that decoration is the basic requirement of the design composition of Chaozhou embroidery, which is determined by the practicality of Chaozhou embroidery.

Chaozhou embroidery has different functions from other embroidery products, mainly in official and folk. Chaozhou embroidery and other embroidery products, including Suzhou embroidery and Hu'nan embroidery, have different uses and functions in history: Suzhou embroidery and Hu'nan embroidery mainly serve the costumes of courts and officials, while Chaozhou embroidery serves the decoration of local houses, ancestral halls and temples. Chaozhou embroidery is based on the far-sighted effect, so the overall feeling is relatively rough; while the official clothes give people the feeling of close range, the embroidery is more delicate, the purpose is different, the appreciation angle is different, and it also produces different effects. The Chaozhou embroidery is heavy, rugged, and durable. Combined with the entire building, it produces a magnificent effect, which shows the wisdom and life longing of the working people in ancient China.

Due to the difference of embroidery materials, five kinds of embroidery can be distinguished in Chaozhou embroidery, namely: nail-gold embroidery, mixed gold and velvet embroidery, velvet embroidery, thread embroidery and foreign gold and silver thread embroidery. The combination of gold and velvet is called mixed embroidery; mainly made of gold and silver thread, and colored wool thread as a supplement, it is called nail-gold embroidery; embroidery with electro-optical yarn or chemical fiber thread is called thread embroidery; and embroidery with hair is called hair embroidery. In short, the materials used in Chaozhou embroidery are rich and varied.

\section{THE DILEMMA FACED BY CHAOZHOU EMBROIDERY}

The main traditional products of Chaozhou embroidery include hanging screens, banners, screens, bed curtains, colored eyebrows, costumes, banners, and treasure covers. It is rare to apply it to modern cultural and creative products. If the Chaozhou embroidery is used as a highly decorative handicraft embroidery, in addition to being used in contemporary high-end custom products, it can also be used in the cultural and creative products of people's contemporary life, such as lamps, bags, mobile phone cases, cups and other product designs, which can directly inject the traditional crafts and culture of Chaozhou embroidery into people's living environment.

However, for the current innovative design of Chaozhou embroidery, the relevant practitioners lack certain modern design ability and experience. At present, the main problems of the Chaozhou embroidery cultural and creative products on the market are that the depth of product culture is not enough, the redesign of traditional culture stays in the superficial form, and the lack of practicality.

First of all, the sense of innovation is not strong, and the integration with current life and modern design is not close enough, which leads to the slow development of the Chaozhou embroidery industry 
today. Chaozhou embroidery is divided into art collections, traditional home furnishings, and important holiday wedding dresses according to the degree of craftsmanship. It is difficult to meet the tastes and needs of young consumer groups in the new era, and there are few daily personal use scenarios. Less use of consumer-grade products means that repeated production and mass production of a single product cannot be formed, and it is difficult to form industrial agglomeration. In Chaozhou, apart from some small-scale Chaozhou embroidery production enterprises in the local area, most of them are family-style studios and workshops mainly composed of middle-aged female embroidery masters. However, most of the traditional Chaozhou embroidery workers have not kept up with the pace of changes in this era, and lack of development, inheritance and innovation in the Chaozhou embroidery market, which makes the innovation and development of the Chaozhou embroidery basically in a state of vacancy in the design of cultural and creative products.

Secondly, in terms of functional application and design aesthetics such as the sense of picture and pattern materials, the Chaozhou embroidery cannot meet the ever-increasing functional demands and contemporary aesthetic requirements of contemporary consumers. It lacks connection with modern and contemporary international standards. It is more about inheritance, less innovation, oldfashioned material design forms, and lack of creativity, which gradually leads to a single product, so it lacks a sense of modernity.

\section{INHERITANCE AND INNOVATION PATH}

The first is inheritance protection and skill training. Many embroidering institutions or inheritors have embroidered the actual needle patterns of the remaining types of work. It is recommended that the project protection unit take the lead to systematically record and save the audio, video and image data of the actual embroidery of old artists in a rescue manner. School-enterprise joint training bases or embroidering skills on campus are all good measures to promote local excellent traditional skills, cultivate interest, and learn. This level of docking can be started from the perspective of industry, academia, and research, and companies, schools, and researchers are docked. This is the point that Chaozhou Mingrui Group has made a link to the wedding and evening dress industry. Mingrui Group is a well-known national wedding and evening dress company. Its characteristic is to apply the intangible cultural heritage of Chaozhou embroidery to dragon and phoenix gowns and Xiuhe, transforming and preserving the maximum industry of Chaozhou embroidery. In the development, Mingrui Group also actively cooperates with the government, universities, and holds various training stations. Enterprises can export skills to schools. Researchers can also extract cultural knowledge from them, feedback the unwritten cultural vacancies, and make the protection of intangible cultural heritage an industrial chain.

The second is the inheritance of productive protection. The most effective protection for intangible cultural heritage is productive protection, which is a kind of living protection, that is, while studying its cultural value, it excavates and reflects its economic value, so that it can serve modern life and expand its demand of modern life. Where there is demand, there is a market, where there is a market, production can be organized, and if there is production, it can survive, rejuvenate, inherit and develop. As a national intangible cultural heritage, Chaozhou embroidery not only has cultural value, but also has economic value that can adapt to modern life and can be productively protected. The first is driven by innovation. The technical innovation of each embroidery type's own theme, materials, techniques and styling and the integration of several local embroidery types simultaneously improve the design, production level and overall quality of the product. The second is that traditional embroidery need to be integrated into modern life and applied to modern cultural and creative products, which is often referred to as grafting fashion. If the Chaozhou embroidery culture wants to go out, it needs to be based on culture and take the road of culture grafting market operation.

Then, it is necessary to aim at the consumer demand of the young group market again, and design cultural and creative products suitable for young people. The design of such Chaozhou embroidery cultural and creative products needs to be interesting, the product design conforms to the daily habits of young consumer groups, and the color and shape characteristics conform to their aesthetic habits. With the continuous increase in the purchasing power of digital content by young consumer groups, the society is paying more attention to digital products such as mobile applications, mobile games, animations, and film and television works. For example, in order to attract young consumers, the Palace Museum has 
developed 9 mobile applications and 11 online games related to the Palace Museum culture. The idea of combining digital IP with traditional culture and put it into practice, such as: Chaozhou embroidery young designer Sun Tiancheng combined Chaozhou embroidery with Tencent Games cross-border. His team has customized the game scenes and character Chaozhou embroidery works for a Tencent game, and has put them on the market, so that some young people who have little knowledge of Chaozhou embroidery have the opportunity to get in touch with this traditional culture. In addition, he is also considering developing Chaozhou embroidery products such as mobile phone shells with embroidered fashion, so that Chaozhou embroidery can truly penetrate the world of young people. The practice of allowing consumers to participate in the re-creation by changing the "gameplay" meets the experiential needs of young consumer groups and interprets innovative thinking that conforms to the business environment of the Internet age. Therefore, it is necessary to make the expensive Chaozhou embroidery become a more acceptable small commodity and realize the sale of the goods, so that young people are interested in this kind of small commodities and are interested in understanding what Chaozhou embroidery is. And then they are willing to spend time learning Chaozhou embroidery, so that they can truly realize the employment and inheritance of Chaozhou embroidery.

\section{DESIGN EXAMPLES}

Through the study and practice of Chaozhou embroidery, the researchers tried to combine the Chaozhou embroidery with the design of cultural and creative products, and designed and produced some cultural and creative works.

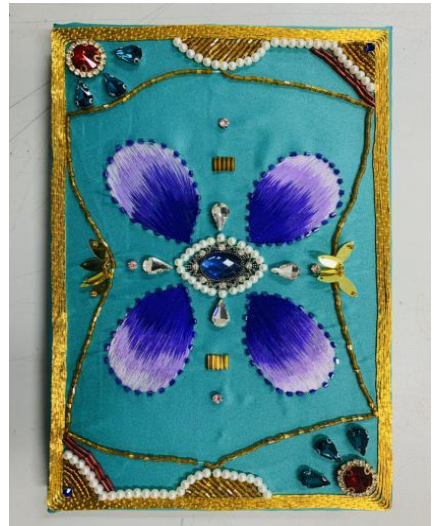

Figure 1 Chaozhou embroidery creative works 1 makeup box.
This cultural and creative work ("Figure 1") is inspired by the carved beams and painted ridges on the traditional architecture. The traditional green background color is used. The gold thread and yellow velvet are used in contrast to embroider gold. The centripetal composition of the gradient color is used in the middle. The clever combination of dots, lines and surfaces makes the makeup box more beautiful. The design of the make-up box uses the technique of combining traditional pan-gold embroidery and bead embroidery in Chaozhou embroidery. The application of traditional embroidery to the decoration of modern cosmetic boxes increases the aesthetics of the product while being practical, and expands the scope of use of cultural and creative products derived from traditional Chaozhou embroidery.

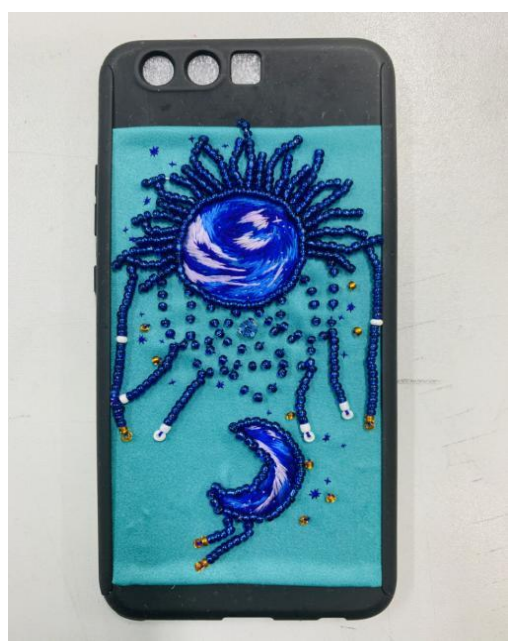

Figure 2 Chaozhou embroidery cultural and creative works 2 - mobile phone shell.

This cultural and creative work ("Figure 2") is inspired by the sun and the moon. It uses the traditional green background color, uses the most basic embroidery methods in the Chaozhou embroidery, velvet embroidery and bead embroidery, to contrast the plane, and the threedimensional method. Velvet embroidery is rich in color changes, with three-dimensional bead embroidery to express the sun's rays, and the broken point in the middle represents the alternation of day and night. In the composition, it presents the form of the sun and the moon echoing each other. The design adopts the technique of combining traditional velvet embroidery and bead embroidery in Chaozhou embroidery, and applies traditional embroidery to the decoration of modern mobile phone shells, which increases the aesthetics of the product and expands the scope of use of 
traditional cultural and creative products derived from Chaozhou embroidery.

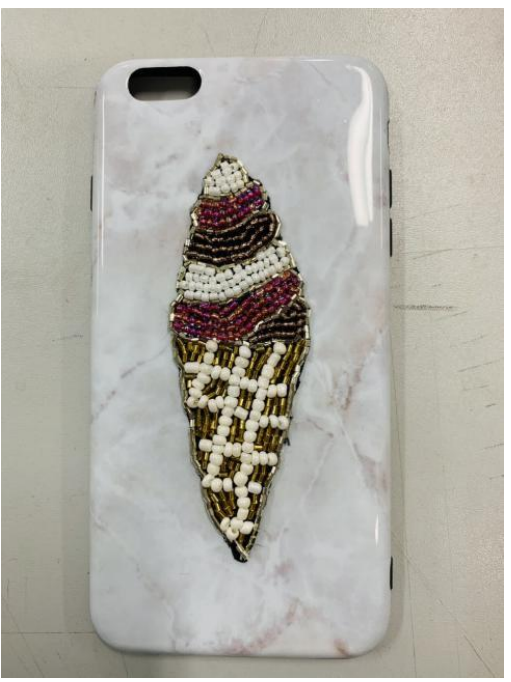

Figure 3 Chaozhou embroidery cultural and creative works 3 - mobile phone shell.
This creative work ("Figure 3") is inspired by torch ice cream, using beads of different colors to express the different flavors and shapes of ice cream, adding layering and fun to the daily mobile phone shell. The combination of traditional embroidery and pearl embroidery is used, and traditional embroidery is applied to the decoration of modern mobile phone shells. The decoration of mobile phone cases is made into three-dimensional, which increases the aesthetics of the product while being practical.

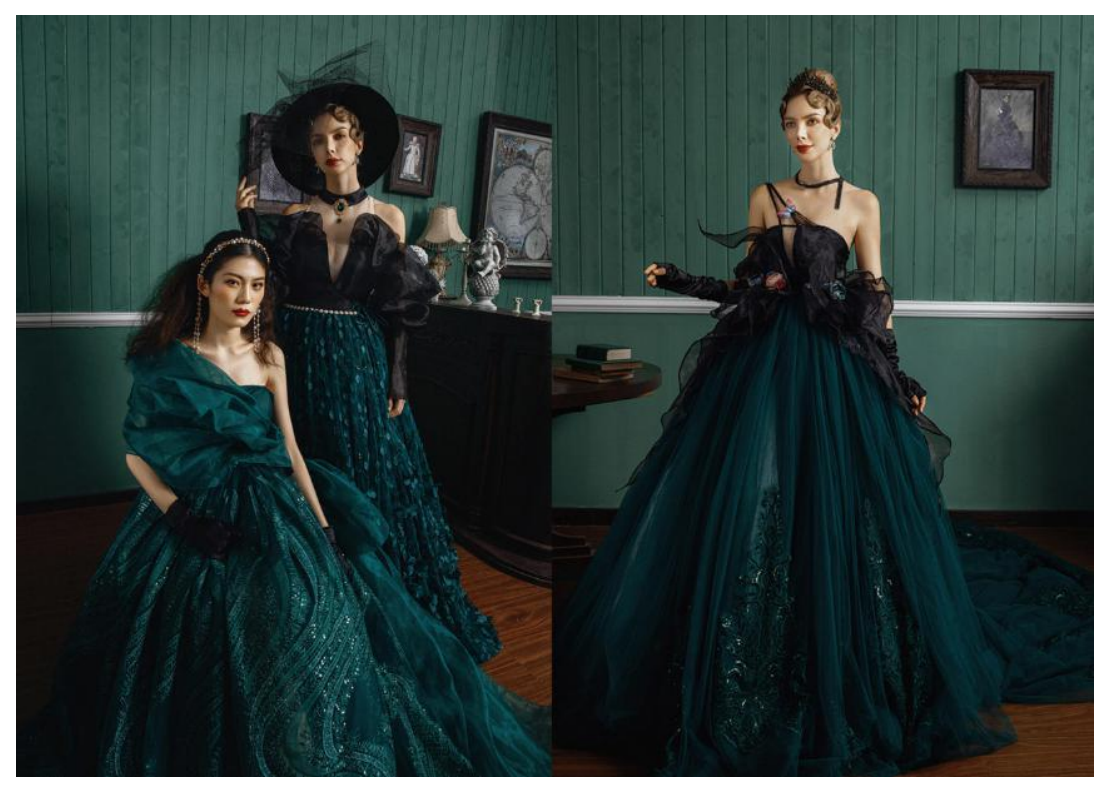

Figure 4 Chaozhou embroidery cultural and creative works 4 - dress.

This series of clothing design ("Figure 4") combines Chaozhou embroidery and pearl embroidery to design and produce modern dresses with retro elements of women's clothing from the 1950 s. Inspired by the retro elements of women's clothing in the 1950s; retro, elegant, and simple styles are used to express the unique beauty of modern women; with the combination of "classical elements + modern decoration", the main feature and expression of the profile is A-shaped; the characteristic of the style is the waist, the big skirt; the classic black and the popular Eden Green are used; in terms of fabrics, traditional French pearl embroidery is combined with new embroidery, using tulle, black lace, organza fabrics, supplemented by embroidery and pearl embroidery, three-dimensional appliques and other fabrics; with yarn as the base, the flat embroidery technique of gilded thread in the Chaozhou embroidery is used to embellish it with pearl embroidery to customize fabrics to make garments. The main crafts used are vertical cutting to make three-dimensional modeling, pearl embroidery, embroidery and hand 
applique embroidery to show contemporary women's elegance.

\section{CONCLUSION}

Chaozhou textile traditional crafts have a long history and a wide variety, embracing a profound history and a long civilization. The Party Central Committee and the State Council attach great importance to the inheritance of traditional culture and crafts, and propose to strengthen the protection of intangible cultural heritage and revitalize traditional crafts, and have outlined a blueprint for future development. Facts have proved that the inheritance, innovation and transformation of Chaozhou embroidery in cultural and creative products are effective. In applying Chaozhou embroidery to the design of cultural and creative products, in addition to absorbing and applying the essence of traditional Chaozhou embroidery design methods and craftsmanship, the most important thing is to innovate and develop contemporary Chaozhou embroidery, and use the essence of Chaozhou embroidery to show the charm and new vitality of Chaozhou embroidery through modern design and modern industrial manufacturing technology. It is also necessary to firmly grasp the organic combination of national characteristics and contemporary design, while satisfying the functionality and aesthetics of cultural and creative products. At the same time, arousing consumer recognition of traditional culture is the long-term development of Chaozhou embroidery cultural and creative products.

\section{AUTHORS' CONTRIBUTIONS}

This article is independently completed by Zhexin Liu.

\section{REFERENCES}

[1] Wang Qishuang, Xu Shiyu, Thoughts on the Development of Qiang eEmbroidery Cultural and Creative Products Against the Background of Intangible Cultural Heritage [J]. China Market, 2019(29). (in Chinese)

[2] Liu Ying, Innovative Transformation and Development of Intangible Cultural Heritage Against the Background of Creative Cultural Consumption - Taking Chao Embroidery as an Example [J]. Today's Mass Media, 2018(7). (in Chinese)
[3] Yu Manshan, Lin Bingjie, Wu Shuzhen, Research on Inheritance and Development of Chao Embroidery [J]. Co-operative Economy \& Science, 207 (4). (in Chinese)

[4] Hu Qiuhua, The Status Quo of Intangible Cultural Heritage and the Way Out - Taking Guang Embroidery as an Example [J]. Think Tank Era, 2019, 4. (in Chinese)

[5] Luo Wanling, A Probe into the Cultivation Mechanism of Fashion Embroidery Talent from the Perspective of Modern Apprentice [J]. Art Education Research, 2018 (05). (in Chinese)

[6] Jiang Qiuping, Analysis on the Paths and Strategies of Live Protection of Guang Embroidery [J]. Art and Literature for the Masses, 2019, 4. (in Chinese)

[7] Wang Bin, Comparative Study and Thinking on the Development Status of Guang Embroidery and Chaozhou Embroidery [J]. Beauty \& Times, 2015(05). (in Chinese)

[8] Li Hongfu, Inheritance and Commercialization of Chaozhou Embroidery [J]. Cultural Heritage, 2010(03). (in Chinese)

[9] Lai Chaowen, On the Protection and Inheritance of Intangible Cultural Heritage: Taking Guangdong Chaozhou Embroidery as an Example [J]. Art Education Research, 2014 (4). (in Chinese) 